\title{
COMPLICAÇÕES DA SÍNDROME FALCIFORME
}

\section{COMPLICATIONS OF SICKLE CELL SYNDROME}

\author{
Sisnayra Cavalcante Cardoso*, Anny Caroline Chaves de Souza Barbosa*, Stephany Nayara \\ Araújo Pinheiro*, Larissa Nathyelle Martins*
}

Autora para correspondência: Sisnayra Cavalcante Cardoso - sisnayra@gmail.com

*Acadêmica de graduação em Enfermagem na UNINORTE, Acre

\section{R E S U M O}

O presente artigo de revisão integrativa aborda e ressalta as principais complicações da anemia falciforme da criança ao adulto. A Síndrome Falciforme é uma importante hemoglobinopatia genética, um tipo de patologia peculiar pela produção de eritrócitos com deformidades falcêmicas, que ocasiona complicações como litíase biliar, crise álgica, crise do sequestro esplênico, acidente vascular cerebral isquêmico, alterações oculares, alterações retinianas. Objetivo: Destacar as principais complicações da anemia falciforme na criança, no adolescente e adultos auxiliando os profissionais de saúde na assistência ao paciente que apresenta essa patologia. Metodologia do estudo: Com a utilização do meio de informação acadêmico via internet de artigos encontrados na (BVS) Biblioteca Virtual em Saúde, foram utilizados os seguintes descritores: Anemia falciforme AND complicações, Doença Falciforme, Anemia Falciforme e Complicações. Pesquisados 7.544 artigos relacionados às complicações da anemia falciforme, na qual 11 são abordados no presente trabalho, com a utilização bibliográfica do Manual de Hematologia, autor Hamerschlak, Nelson e no Manejo das complicações agudas da doença falciforme conforme Brunetta et al. Resultados: As complicações que predominaram em crianças no presente estudo foi a hipertrofia adenotonsilar obstrutiva acometendo mais de $55 \%$ e em adolescentes e adultos foram as alterações oculares com mais de $73 \%$ dos clientes. Conclusão: Embora a patologia falciforme seja pouco discutida e de grande prevalência no Brasil devido a miscigenação racial, o presente estudo ressalta as principais complicações causadas pela mesma, tendo as crianças que apresentam uma prevalência de hipertrofia adenotonsilar obstrutiva acima de $55 \%$ mostrado no seguinte estudo, na qual o profissional de saúde deve estar atento a sintomatologia para que haja o tratamento adequado e as informações fornecidas aos pais ou responsáveis sejam adequadas para cada cliente. $O$ adulto portador da anemia falciforme tem como principal complicação alterações oculares $73 \%$, na qual $\circ$ cuidador deve ter atenção a essas ocorrências.

Palavras-chave: Síndrome falcêmica; complicações da criança ao adulto; profissionais de saúde. 
The present integrative review article discusses and highlights the main complications of sickle cell anemia in children and adults. The Sickle Cell Syndrome is an important genetic hemoglobinopathy, with a peculiar pathology resulting in the production of red blood cells with sickle cell deformities, which causes complications such as gallstones, pain crisis, the splenic sequestration crisis, stroke, ischemic stroke, ocular and retinal changes. Objective: To emphasize the major complications of sickle cell anaemia in children and adults helping health professionals in patient care. Study Methodology: internet articles were searched in (BVS) Virtual Health Library, employing the following descriptors: Sickle cell anaemia AND complications, sickle cell disease, sickle cell disease and complications. 7,544 articles related to complications of sickle cell anaemia were surveyed, in which 11 are addressed in this work in light of the instructions from the Hematology Manual, by Nelson Hamerschlak, and the article on management of acute complications of sickle cell disease by Brunetta et al. Results: Complications that predominated in children in this study was the obstructive adenoid tonsil hypertrophy, affecting over $55 \%$ in the samples of the studies and in adolescents and adults the eye changes were found in more than $73 \%$ of the patients. Conclusion: sickle cell disease is little discussed and highly prevalent in Brazil due to miscegenation, this study highlights the main complications caused by the disease, which health professionals should be aware of so that there is proper treatment and information provided to parents or guardians. The caregiver must have attention to such consequences of sickle cell disease in adults as well.

Keywords: Sickle cell syndrome; Complications in children; Complications in adults; Health professionals. 


\section{INTRODUÇÃO}

É uma das doenças hereditárias mais comuns no Brasil. Afeta, principalmente, a população que apresenta grande miscigenação racial. Aproximadamente 1 criança afro-brasileira em cada 37400 nasce com a doença falciformel. A doença falciforme é uma hemoglobinopatia hereditária, autossômica, caracterizada por substituição de um aminoácido (valina por ácido glutâmico) no sexto códon da cadeia beta da globina, resultando em hemoglobina $\mathrm{S}(\mathrm{HbS})$.

As doenças falciformes mais frequentes são: anemia falciforme (homozigose HbSS), hemoglobina SC (heterozigose $\mathrm{HbS}$ e $\mathrm{HbC}$ ) e traço falciforme (heterozigose $\mathrm{HbS})^{2}$. São várias as complicações agudas na doença falciforme: crises vaso-oclusivas, infecções por microorganismos encapsulados, principalmente do trato respiratório e septicemia, síndrome torácica aguda, sequestro esplênico, priapismo, Acidente Vascular Cerebral (AVC) e crise aplástica.3 Ressaltando estas complicações na criança ao adulto, auxiliando assim os profissionais na assistência ao paciente que apresenta essa patologia. As características de crises álgicas desses pacientes com 12,5 e 14 anos, predominaram crises moderadas $44,7 \% 4$.

A frequência de colelitíase na população estudada foi de $45 \% .5 \mathrm{Em}$ relação a crise do sequestro esplênico varia conforme a região estudada, acometendo $30 \%$ dos pacientes jamaicanos, $7,5 \%$ dos americanos.6 A maior incidência ocorre em crianças de $2-5$ anos com $22 \%$ de lesões vasculares cerebrais na anemia falciforme ${ }^{7}$.

Em pacientes com alterações oculares a idade variou de 8 a 75 anos, com predominância de pacientes entre 16 e 45 anos $(73,3 \%)$ e média de 31,4 anos. 8 Encontrou alterações retinianas em jovens portadores da anemia falciforme de idade entre 14,4 versus 17,4 anos com uma porcentagem de $62,3 \% 9$. Dados retrospectivos mostram que cerca de $28 \%$ a $38 \%$ pacientes apresentam histórico de priapismo $^{10}$.

A prevalência da hipertrofia adenotonsilar obstrutiva foi de 55,3\% co com idade entre 2 e 19 anos $^{11}$. Cerca de $54,8 \%$ das crianças tiveram um único episódio de Síndrome torácica aguda, com pacientes de 5 a 9 anos $^{12}$. Paladino, Silva (2007) As úlceras de membros inferiores são complicações frequentes em adultos com doença falciforme, ocorrem entre $8 \%$ a $10 \%$ dos pacientes homozigotos, acima dos 10 anos $^{13}$.

\section{Anemia Falciforme e Complicações}

A doença falciforme é uma das enfermidades mais antigas da humanidade, decorrente de uma mutação genética ocorrida, majoritariamente, no continente africano. A imigração forçada dos africanos em decorrência do escravismo trouxe - gene a todo território brasileiro. Desse modo, percebe-se que a doença é hereditária, incurável e de alta morbidade e mortalidade, sendo seu tratamento tradicionalmente compreendido, como de competência dos centros hematológicos ${ }^{14}$ é uma das doenças hereditárias mais comuns no Brasil. Afeta, principalmente, a população que apresenta grande miscigenação racial.

Aproximadamente 1 criança afro-brasileira em cada 37400 nasce com a doença falciforme ${ }^{15}$. A doença falciforme é uma hemoglobinopatia hereditária, autossômica, caracterizada por substituição de um aminoácido (valina por ácido glutâmico) no sexto códon da cadeia beta da globina, resultando em hemoglobina $\mathrm{S}(\mathrm{HbS})$. As doenças falciformes mais frequentes são: anemia falciforme (homozigose $\mathrm{HbSS}$ ), hemoglobina SC (heterozigose $\mathrm{HbS}$ e $\mathrm{HbC}$ ) e traço falciforme (heterozigose $\mathrm{HbS})^{16}$. Suas alterações ocasionam vaso-oclusão, resultando em isquemia, inflamação, disfunções, dor e hemólise crônica, gerando danos irreversíveis, comprometendo a qualidade de vida.

\section{MÉTODOS}

O presente artigo se trata de um artigo de revisão integrativa que foram utilizados os métodos retrospectivo e longitudinal. Com a utilização do meio de informação acadêmica via internet de artigos de Bases de dados Literatura Latina Americana e do Caribe em Ciências da Saúde (LILACS), Base 
de dados da Enfermagem (BDENF), Sistema de Análise de Literatura Médica (MEDLINE), Scientific Eletronic Library Online (SCIELO), encontrados na Biblioteca Virtual em Saúde (BVS). Selecionados artigos de 2007 à 2015, idiomas: português e inglês. Utilizando o seguintes descritores: Anemia falciforme AND complicações, Anemia Falciforme e Complicações.

Através destes descritores houve uma recuperação de um número maior de referência relacionado ao tema detectando se assim uma quantidade significativa de trabalhos dentro dos critérios préestabelecidos.

Considerando estas informações e sendo analisadas especificamente de cada artigo relacionada ao título do artigo, autoria, ano de publicação e revista os critérios de inclusão no estudo foram artigos científicos de pacientes portadores da síndrome falciforme e suas complicações nas seguintes faixa etária 3 meses de idade à 45 anos.

Pesquisados 7.544 artigos relacionados às complicações da anemia falciforme, através da filtragem que a BVS disponibilizou, na qual restaram 11 artigos que preencheram $\circ$ requisitos da pré-seleção para a elaboração do presente trabalho, não foram incluídos os outros artigos pois os mesmos apresentavam diagnóstico, prognóstico, tratamento, epidemiologia que não é o objetivo deste artigo, com a utilização bibliográfica do Manual de Hematologia, autor Hamerschlak, Nelson e no Manejo das complicações agudas da doença falciforme conforme Brunetta et al.

As informação colhidas foram sistematizadas em banco de dados eletrônicos, no programa Microsoft Excell, Windows 2013.

\section{RESULTADOS}

A Anemia Falciforme constitui um amplo obstáculo na saúde pública em países subdesenvolvidos ou em desenvolvimento. É uma das doenças genéticas mais comuns no Brasil. Influencia, principalmente na população que apresenta uma extensa miscigenação racial. As complicações dessa síndrome é um dos motivos que levam as crianças 6 anos e 7 meses ao atendimento pediátrico, devido à crise álgica moderada com cerca de $44,7 \%{ }^{18}$.

O sequestro esplênico varia sua incidência conforme a localidade, sendo mais frequente dos 3 meses a 5 anos, por exemplo os jamaicanos são acometidos cerca de $30 \%$ e os americanos $7,5 \%{ }^{17}$.

Pode se afirmar que 0 acidente vascular cerebral isquêmico influenciou, no desenvolvimento e na peculiaridade de vida da criança com faixa etária de 2 a 5 anos com $22 \%^{7}$. As alterações oculares e eletrorretinográficas na anemia falciforme, mostrase uma predominância na idade entre 16 e 45 anos com $73,3 \%^{8}$.

Foi encontrado um número elevado em pacientes com colelitíase de 12,5 e 14 anos com $45 \%{ }^{5}$.

Encontrou alterações retinianas em jovens portadores da anemia falciforme de idade entre 14,4 versus 17,4 anos com uma porcentagem de $62,3 \%$. Capacidade funcional (dor osteomuscular) prevaleceu $5 \%$ dos pacientes com faixa etária 31 , 77 anos $^{13}$. Mostra Cerca de $28 \%$ a $38 \%$ pacientes que apresentam histórico de priapismo ${ }^{14}$. A prevalência da hipertrofia adenotonsilar obstrutiva foi de 55,3\%, com idade de 2 e 19 anos $^{15}$. Cerca de $54,8 \%$ das crianças tiveram um único episódio de Síndrome torácica aguda, com pacientes de 5 a 9 anos $^{16}$.

As úlceras de membros inferiores são complicações frequentes em adultos com doença falciforme, ocorrem entre $8 \%$ a $10 \%$ dos pacientes homozigotos, acima dos 10 anos $^{17}$.

Verifica-se na tabela 1 o título, $\circ$ autor, $\circ$ ano de publicação e a revista na qual foram utilizados no respectivo trabalho. 
Tabela 1. Mostra o título, autor, ano de publicação e revista que foram utilizados no presente trabalho.

\begin{tabular}{|c|c|c|c|}
\hline TíTULO & AUTOR & ANO DE PUBLICAÇÃO & REVISTA \\
\hline $\begin{array}{l}\text { Litíase biliar em } \\
\text { crianças com } \\
\text { doença falciforme } \\
\text { acompanhados } \\
\text { em um centro de } \\
\text { hematologia no } \\
\text { Brasil. }\end{array}$ & Gumeiro; Brandão; Pinto. & 2008 & $\begin{array}{c}\text { Arquivos } \\
\text { de gastroentereologia. }\end{array}$ \\
\hline $\begin{array}{l}\text { Crise álgica } \\
\text { em crianças } \\
\text { portadoras de } \\
\text { anemia falciforme. }\end{array}$ & Oliveira et al. & 2015 & Revista médica Minas Gerais \\
\hline $\begin{array}{l}\text { Crise de sequestro } \\
\text { esplênico na } \\
\text { doença falciforme. }\end{array}$ & Bruneira. & 2007 & $\begin{array}{c}\text { Revista brasileira de } \\
\text { hematologia e hemoterapia }\end{array}$ \\
\hline $\begin{array}{c}\text { Acidente Vascular e } \\
\text { outras complicações } \\
\text { do sistema nervoso } \\
\text { central nas doenças } \\
\text { falciformes }\end{array}$ & Angulo. & 2007 & $\begin{array}{c}\text { Revista brasileira de } \\
\text { hematologia e hemoterapia }\end{array}$ \\
\hline $\begin{array}{l}\text { Alterações } \\
\text { oculares e } \\
\text { letrorretinográficas } \\
\text { na doença } \\
\text { falciforme. }\end{array}$ & David; Haroldo; Rodrigues & 2011 & $\begin{array}{c}\text { Arquivos brasileiros de } \\
\text { oftalmologia }\end{array}$ \\
\hline $\begin{array}{l}\text { Alterações } \\
\text { Retinianas em } \\
\text { jovens portadores } \\
\text { de anemia } \\
\text { falciforme }\end{array}$ & Santos et al. & 2012 & $\begin{array}{c}\text { Arquivos brasileiros de } \\
\text { oftalmologia }\end{array}$ \\
\hline Dor osteomuscular & Ohara et al. & 2012 & $\begin{array}{c}\text { Revista Brasileira de } \\
\text { Fisioterapia }\end{array}$ \\
\hline Priapismo & Vicari; Figueiredo & 2007 & $\begin{array}{c}\text { Revista Brasileira de } \\
\text { Hematologia e Hemoterapia }\end{array}$ \\
\hline $\begin{array}{l}\text { Hipertrofia } \\
\text { Adenotonsilar }\end{array}$ & Salles et al. & 2009 & Jornal de Pediatria \\
\hline $\begin{array}{c}\text { Síndrome Torácico } \\
\text { Aguda }\end{array}$ & García et al. & 2014 & $\begin{array}{c}\text { Revista Cubana de } \\
\text { Hematología, Inmunología y } \\
\text { Hemoterapia }\end{array}$ \\
\hline $\begin{array}{l}\text { Úlcera de membros } \\
\text { inferiores }\end{array}$ & Paladino et al. & 2007 & $\begin{array}{c}\text { Revista Brasileira de } \\
\text { Hematologia e Hemoterapia }\end{array}$ \\
\hline
\end{tabular}

\section{DISCUSSÃO}

As diversas complicações da anemia falciforme ressaltam sua importância ao profissional de saúde público/privado relacionado ao atendimento destes pacientes. No gráfico 1 observa-se a prevalência da crise álgica em criança de 6 e 7 anos com índice de $44,7 \%$ apresentado por Oliveira et al.(2015) de pacientes com esse sintoma. De acordo com Bruneira (2007) 30\% dos pacientes de 3 meses a 5 anos de idade apresentaram crise do sequestro esplênico.
O acidente vascular cerebral isquêmico teve uma prevalência baixa de $22 \%$ na faixa etária de 2 a 5 anos Angulo (2007).

No gráfico 3 os autores David; Haroldo; Rodrigues ${ }^{8}$ demonstraram em suas pesquisas um elevado número de adolescentes e adultos com $73 \%$ entre 16 a 45 anos com alterações oculares. Segundo Santos 9 as alterações retinianas em pacientes com 14,4 e 17,4 anos são de $62,30 \%$. A colelitíase relatada na pesquisa de Gumeiro ${ }^{6}$, teve $\circ$ índice de $45 \%$ na 
idade de 12,5 e 14 anos, porém Ohara' ${ }^{13}$ mostra que a capacidade funcional (dor osteomuscular) obteve um índice baixo de $5 \%$ na idade de 31,77 anos. Vicari e Figueiredo ${ }^{14}$ cerca de $28 \%$ a $38 \%$ dos pacientes apresentam histórico de priapismo, com idade até os 20 anos. Conforme Salles ${ }^{15}$ a prevalência da hipertrofia adenotonsilar obstrutiva foi de 55,3\% entre 2 a 19 anos. García et al ${ }^{16}$. cerca de $54,8 \%$ das crianças tiveram um único episódio de Síndrome torácica aguda, com pacientes de 5 a 9 anos. Paladino, Silva ${ }^{17}$.

As úlceras de membros inferiores são complicações frequentes em adultos com doença falciforme, ocorrem entre $8 \%$ a $10 \%$ dos pacientes homozigotos, acima dos 10 anos.

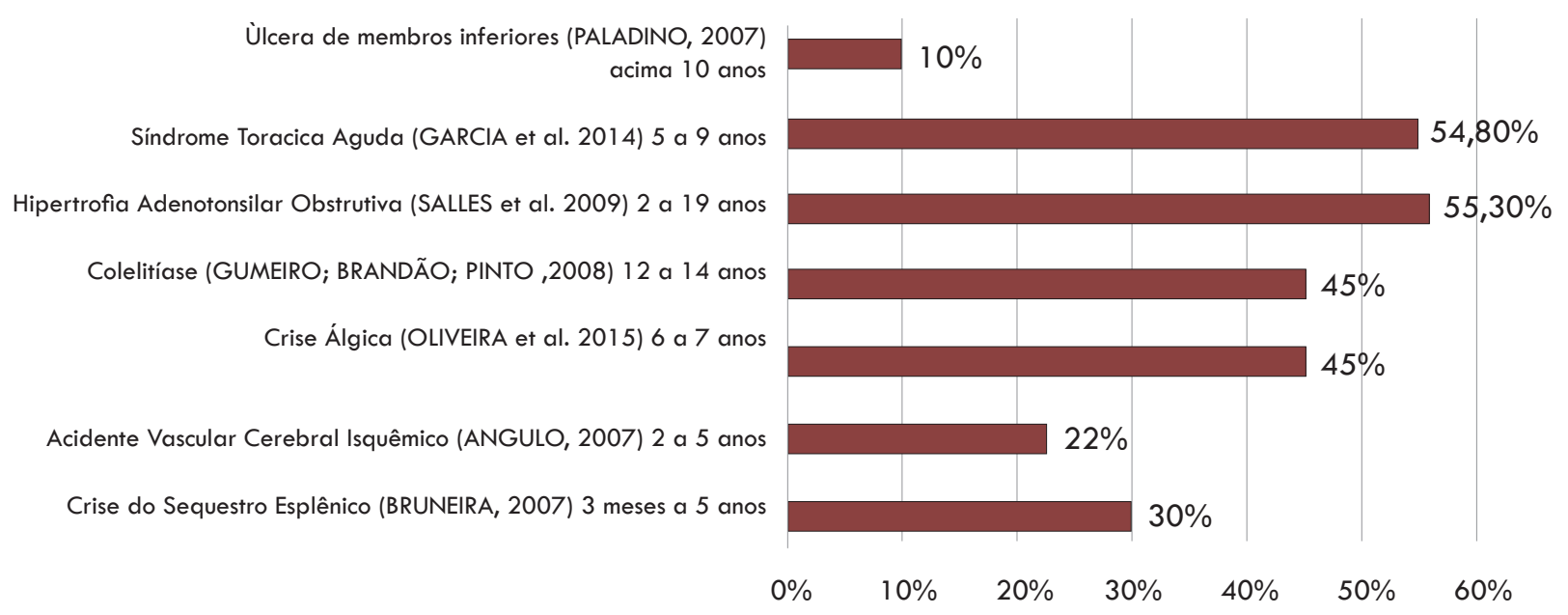

Gráfico 1. As principais complicações da Síndrome Falcêmica na criança.

\section{Complicações no Adolescente e no Adulto}

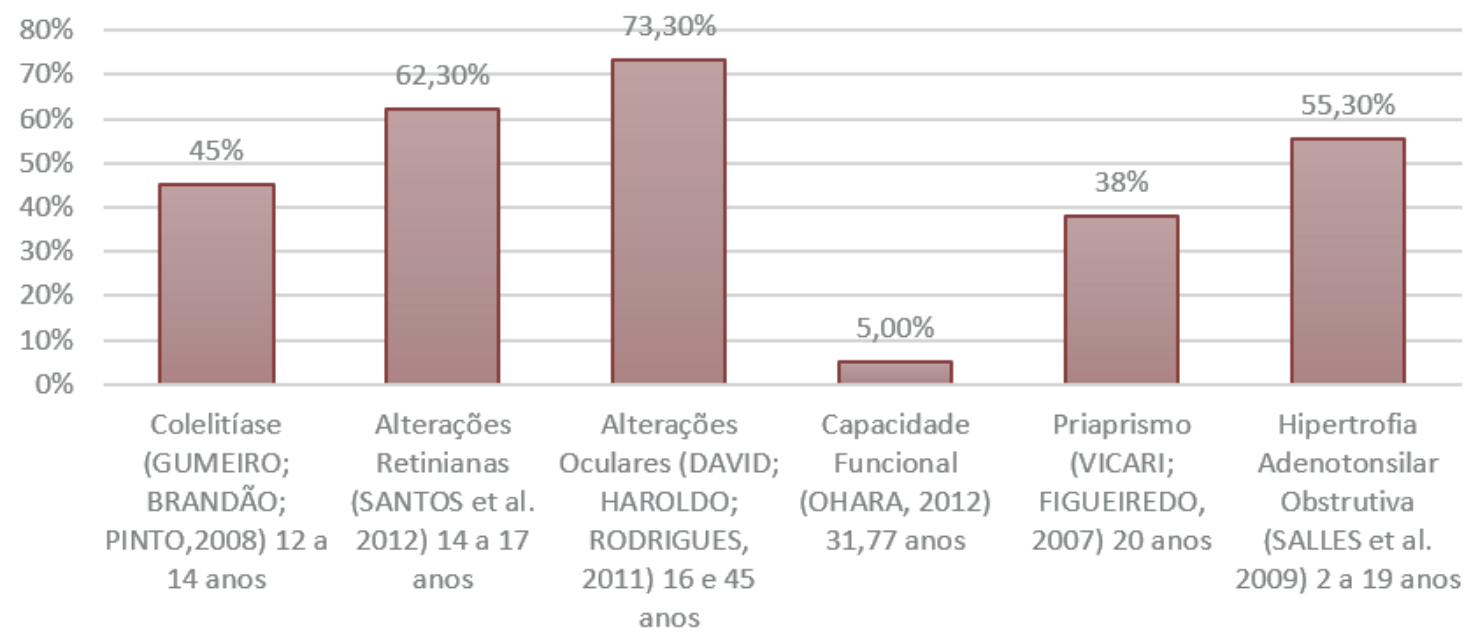

Gráfico 2. As principais complicações da Síndrome Falcêmica no adolescente e no adulto. 


\section{CONCLUSÃO}

Embora a patologia falciforme seja pouco discutida e de grande prevalência no nosso país devido a miscigenação racial, traz um foco da sociedade para estes pacientes com complicações que a mesma ocasiona, tendo estes pacientes, as crianças que apresentam uma prevalência de crise álgica mostrado no seguinte estudo, o profissional de saúde deve estar atento a sintomatologia para que haja o tratamento adequado e as informações fornecidas aos pais ou responsáveis.

O adulto portador da anemia falciforme tem como principal complicação alterações oculares, na qual o cuidador deve ter atenção essas ocorrências.

\section{REFERÊNCIAS}

1. Silva LPA, Nova CV, Lucena R. Anemia falciforme e surdez infanto-juvenil: revisão da literatura. Braz. j. otorhinolaryngol. 2012.78(1):126-131. doi: $10.1590 / \mathrm{S} 1808-86942012000100020$

2. Hamerschlak N. Manual de Hematologia. São Paulo: Manole; 2010. P. 51

3. Brunetta DM, Clé DV, Haes TM, Roriz-Filho JS, Moriguti JC. Manejo das complicações agudas da doença falciforme. Medicina (Ribeirão Preto). 2010;43(3):231-7

4. Silva DG, Marques IR. Intervenções de enfermagem durante crises álgicas em portadores de Anemia Falciforme. Rev. bras. enferm. 2007;60(3):327-330. doi: 10.1590/S003471672007000300015

5. Bruniera P. Crise de seqüestro esplênico na doença falciforme. Rev. Bras. Hematol. Hemoter. 2007;29(3):259-261. doi: 10.1590/S151684842007000300012 .

6. Gumiero APS, Bellomo-Brandao MA, Costa-Pinto EAL. Gallstones in children with sickle cell disease followed up at a Brazilian hematology center.
Arq. Gastroenterol. 2008;45(4):313-318. doi: $10.1590 /$ S0004-28032008000400010

7. Ângulo IL. Acidente vascular cerebral e outras complicações do sistema nervoso central nas doenças falciformes. Rev. bras. hematol. Hemoter. 2007;29(3):262-267. doi: 10.1590/S151684842007000300013

8. David RC, Junior HVM, Rodrigues MPM. Alterações oculares e eletrorretinográficas na doença falciforme. Arq. Bras. Oftalmol. 2011 ;74(3):190-194. doi: 10.1590/S000427492011000300009

9. Santos $A M$, Faro GBA, Amaral MVM, Mendonça $C Q$, Leal BC, Cipolotti R. Alterações retinianas em jovens portadores de anemia falciforme (hemoglobinopatias) em hospital universitário no nordeste do Brasil. Arq. Bras. Oftalmol. 2012;75(5):313-315. doi: 10.1590/S000427492012000500003

10. Kikuchi BA. Assistência de enfermagem na doença falciforme nos serviços de atenção básica. Rev. Bras. Hematol. Hemoter. 2007;29(3):331-338. doi: 10.1590/S1516-84842007000300027

11. Silva LPA, Nova CV, Lucena R. Anemia falciforme e surdez infanto-juvenil: revisão da literatura. Braz. j. otorhinolaryngol. 2012;78(1):126-131. doi: 10.1590/S180886942012000100020

12. Hamerschlak N. Manual de Hematologia. São Paulo: Manole; 2010. P.51.

13. Ohara DG, Ruas G, Castro SS, Martins PRJ, Walsh IAP. Dor osteomuscular, perfil e qualidade de vida de indivíduos com doença falciforme. Rev. bras. fisioter. 2012 ; 16(5):431-8. doi: 10.1590/ S1413-35552012005000043

14. Vicari P, Figueiredo MS. Priapismo na doença falciforme. Rev. Bras. Hematol. Hemoter. 2007;29(3):275-278. Doi: 10.1590/S151684842007000300016

15. Salles Cristina, Ramos RTT, Daltro C, Nascimento $V M$, Matos MA. Associação entre hipertrofia adenotonsilar, tonsilites e crises álgicas na anemia 
falciforme. J. Pediatr. (Rio J.). 2009;85(3):249-253.

doi: $10.1590 /$ S0021-75572009000300011

16. Garcia WR, Svarch E, Laferté YQ, Díaz AG. Síndrome torácico agudo en niños con drepanocitosis en el Instituto de Hematología e Inmunología. Rev Cubana Hematol Inmunol Hemoter. 2014;30(2):137-145

17. Paladino Silvia F. Úlcera de membros inferiores na anemia falciforme. Rev. Bras. Hematol. Hemoter. 2007;29(3):288-290. doi: 10.1590/S151684842007000300019

18. Sousa GGO, Fonseca FF, Regis ET, Junior LCBG, Grunewald STF. Crise álgica em crianças portadoras de doença falciforme. Rev. méd. Minas Gerais. 2015;25(Supl 6): S23-S27. doi: $10.5935 / 2238-3182.20150093$ 